\title{
The outcome of hydrodilation in frozen shoulder patients and the relationship with kinesiophobia, depression, and anxiety
}

\author{
Philippe Debeer ${ }^{1,2,3^{*}}$ D , Olivia Commeyne ${ }^{4}$, lanthe De Cupere ${ }^{4}$, Dorien Tijskens ${ }^{1,2,3}$, Filip Verhaegen ${ }^{1,2,3}$, \\ Wim Dankaerts ${ }^{4}$, Laurence Claes $^{5,6}$ and Glenn Kiekens ${ }^{5,7}$
}

\begin{abstract}
Purpose: The aims of this study were to (1) investigate the effect of hydrodilatation in frozen shoulder patients on objective indices of shoulder functionality and subjective outcomes of pain, mobility, kinesiophobia, depression, and anxiety, and (2) progress knowledge about the reciprocal temporal relationship between psychological parameters at baseline and objective and subjective outcomes at 3-month follow-up.

Methods: We evaluated the clinical and psychological status of 72 patients with a frozen shoulder before and after hydrodilatation, using the Constant Murley score, the Visual Analogue score, the Tampa Scale for Kinesiophobia, the Hospital Anxiety and Depression Scale, and the Shoulder Pain And Disability Index.

Results: We noted a significant improvement in functionality, pain and disability $(p<.001)$. Depression and anxiety improved significantly $(p<.001)$ between baseline and 3-month follow-up. Prospective analyses demonstrated that psychological factors are more likely to predict outcomes of hydrodilatation than vice versa.

Conclusion: Hydrodilatation followed by physiotherapy is an excellent way to treat patients with recalcitrant frozen shoulder, resulting in a continuous improvement of ROM and pain. Physiotherapists and physicians should be aware that psychological factors might have an impact on the treatment outcome.
\end{abstract}

Keywords: Frozen shoulder, Depression, Anxiety

\section{Background}

Psychosocial factors are frequently present in patients with shoulder complaints and might play a role in the disease, the perception of pain and disability, and the functional outcome after surgery [16]. The chronicity of the complaints often negatively impacts the quality of life and physical and mental well-being. Kinesiophobia, negative pain belief, low pain efficacy, and catastrophizing can be associated with higher levels of pain and disability in the upper extremity problems $[9,25]$. Similarly,

\footnotetext{
*Correspondence: Philippe.debeer@uzleuven.be

1 Orthopedics, University Hospitals Leuven, Herestraat 49, B-3000 Leuven, Belgium

Full list of author information is available at the end of the article
}

depression has been associated with worse surgical outcomes in several musculoskeletal conditions and seems to be more prevalent in orthopaedic patients than in the general population [8]. More specifically, in patients with shoulder problems, depression and anxiety can negatively influence health-related quality of life and are associated with higher levels of functional disability and a longer duration of symptoms [5, 22]. Some studies demonstrate worse postoperative outcomes in patients with anxiety and depression, whereas others found no influence of these psychological parameters after shoulder surgery $[6$, $11,17,19]$.

This study focuses on patients with frozen shoulder, a disabling condition of the shoulder characterized by often severe pain and functional restriction of both active 
and passive shoulder motion for which radiographs of the glenohumeral joint are essentially unremarkable. Although some patients with a frozen shoulder improve without any intervention, the majority of patients continue to have pain and/or restriction of mobility [26]. Similar observations were made by Abrassart et al. [1]. These authors concluded that the natural history of frozen shoulder often sees short-term improvement but bears a high chance of ongoing low-level restriction and pain. The condition can be primary or idiopathic, or secondary, indicating a specific cause [28]. Treatment options for frozen shoulder include physiotherapy, injections, hydrodilatation, manipulation under anesthesia, and capsular release. Hydrodilatation consists of injecting fluid in the glenohumeral joint under fluoroscopic control to rupture the capsule to increase the shoulder's mobility [2]. It is an easy, safe, and cost-effective method to treat frozen shoulder in terms of functionality and pain relief $[4,14,15,20,21,27]$. Moreover, when a first hydrodilatation does not result in adequate pain relief and/or restoration of mobilty, the procedure can easily be repeated before proceeding to a surgical procedure.

Clinicians often have the impression that patients with a frozen shoulder have a specific personality and tend to be neurotic, tense and have a low pain threshold. In a previous study, we could not confirm the assertion that such a 'frozen shoulder personality' exists [10]. Several studies found that psychosocial factors like depression, anxiety, and kinesiophobia are frequently associated with frozen shoulder $[12,13]$. While these studies provide meaningful information about the mental health comorbidity of patients with a frozen shoulder, they are all cross-sectional, which limits the conclusions we can draw about the directionality of effects (i.e., whether depression and anxiety predict objective and subjective frozen shoulder outcomes, or whether these outcomes increase the risk of worse mental health problems, or both).

The present study has two primary aims. First, we wanted to confirm the beneficial effect of hydrodilatation in frozen shoulder patients on objective indices of shoulder functionality and subjective outcomes of pain, mobility, kinesiophobia, depression, and anxiety. We hypothesized that a hydrodilatation would increase the shoulder's functionality, decrease the pain and that the psychological parameters would negatively influence the outcome. Second, we investigated whether anxiety, depression, and kinesiophobia at baseline negatively predict the objective and subjective outcomes of hydrodilatation at 3-month follow-up, and that worse objective and subjective outcomes of hydrodilation positively predict worse mental health complaints at 3-month followup. Specifically, we hypothesized that higher levels of kinesiophobia, depression, and anxiety would attenuate the objective and subjective outcomes of hydrodilation, and vice versa, that improvement in objective and subjective clinical parameters would lead to less kinesiophobia, depression, and anxiety at three-month follow-up.

\section{Methods \\ Participants}

We prospectively enrolled patients who presented to our Orthopaedic Upper Limb Clinic with a frozen shoulder between September 2014 and January 2018. The diagnosis of frozen shoulder was made on clinical grounds. Based on the criteria of Zuckerman and Rokito, patients were further subdivided into a primary and a secondary frozen shoulder group [28]. All participants provided written informed consent before inclusion in the study. This study was approved by the Full Local Research and Ethical Committee of the University Hospital of Leuven (B322201421602; S56800).

\section{Assessments and instruments}

The active and passive mobility of both the affected and unaffected shoulder was recorded using a goniometer with the patient standing. Active internal rotation at the back was measured by recording the vertebral level reached with the thumb's tip. This level was serially numbered 1 to 12 for $\mathrm{T} 1$ to T12; 13 to 17 for L1 to L5, and 18 for any level below the sacral region.

All patients had radiographs of the shoulder to detect any bony abnormalities or rotator cuff calcifications. We used ultrasound and magnetic resonance to evaluate any other underlying pathology. Exclusion criteria were stiffness caused by glenohumeral osteoarthritis, reflex sympathetic dystrophy of the ipsilateral hand, stiffness after shoulder arthroplasty, malignant neoplasms of the shoulder girdle, and mental incapacity to fill in the questionnaires.

\section{Clinical assessment}

Functionality of the shoulder was assessed using the Constant-Murley Score (CMS) [7]. The Shoulder Pain And Disability Index (SPADI) was used to measure pain and disability [23]. The SPADI is a self-report questionnaire and contains two domains: pain (five items) and disability (eight items). All patients completed the Hospital Anxiety and Depression Scale (HADS) to determine anxious and depressive symptomatology. The HADS assesses anxiety and depression in non-psychiatric patients, with higher scores indicating higher levels of anxiety and depression symptoms [3]. We used the short version of the Tampa Scale for Kinesiophobia (TSK-11) to evaluate the degree of kinesiophobia. Higher scores indicate higher levels of kinesophobia [24]. The pain level was assessed with the Visual analogue Score (VAS). 
All patients were examined clinically before the hydrodilatation (time-point T1), immediately after the hydrodilatation (time-point T2), and three months after hydrodilatation (time-point T3). The VAS, HADS, SPADI and TSK-11 were completed at $\mathrm{T} 1$ and $\mathrm{T} 3$.

\section{Hydrodilatation}

At our institution, hydrodilatation is prescribed by the orthopaedic surgeon (PD, FV) for patients with adhesive capsulitis with persistent pain and stiffness. A musculoskeletal radiologist performed hydrodilatation under fluoroscopic guidance with the patient supine on the table. A 21-gauge needle was inserted in the glenohumeral joint, the intra-articular position was confirmed with $5 \mathrm{~mL}$ contrast medium (Ultravist) and a mixture of $40 \mathrm{mg}$ methylprednisolonacetate, $15 \mathrm{~mL}$ of local anesthetic (marcaine $0.5 \%$ ), and $20 \mathrm{~mL}$ of normal saline was slowly injected until the capsule was ruptured, as demonstrated on the fluoroscopy monitor by extracapsular leakage of the contrast medium. A physiotherapist recorded the active and passive mobility of the shoulder at T1 and T2. All patients received a standardized physiotherapy protocol to perform under the supervision of their local physiotherapist. The protocol typically consists of gentle active and passive shoulder mobilization exercises within the tolerated range together with stretching exercises for the chest muscles and muscles at the back of the shoulder. Aggressive exercises should be avoided, because they can worsen the capsular synovitis and subsequently cause pain. Strengthening exercises for the rotator cuff, the deltoid, the chest muscles and the scapulothoracic musculature can be started when the range of motion is gradually improving.

\section{Statistical analysis}

We used the expectation-maximization method to account for missing data $(\max 5$ cases/variable). To evaluate the potential beneficial effect of hydrodilatation on objective and subjective outcomes (objective one), we calculated change scores of active and passive ROM, perceived pain, disability associated with shoulder pathology, depression, anxiety, and kinesiophobia. Significant changes over time for each of these variables were assessed using repeated measure ANOVAs with time as a within-subject variable. In a second step, we evaluated the moderating role of age, sex, and type of frozen shoulder in a multivariate model to clarify the generality of the effects of hydrodilatation. These effects were considered significant at $\alpha=0.05$.

We performed multivariate linear regressions to investigate the reciprocal temporal effects between objective and subjective outcomes of hydrodilatation on the one hand, and depression, anxiety, and kinesiophobia on the other hand (objective two). These analyses predicted clinical outcomes at T3 and included each time the dependent variable's score at pre-assessment, age, sex, and frozen shoulder type. This method allowed us to investigate each independent variable's incremental predictive effect on each outcome of interest. We used 95\% bias-corrected and accelerated bootstrap confidence intervals to identify significant predictors. All analyses were performed using SPSS version 26.

\section{Results}

A total of 72 patients, 44 women and 28 men with a mean age of 53 years ( $S D=7$, range, 38-70 years) were enrolled in this study. The median time that patients had complaints was eight months (Interquartile range $=5.3-12.0$ ). Twenty-five patients had an idiopathic frozen shoulder. The group of secondary frozen shoulders $(n=47)$ was very heterogeneous. Nine patients had diabetes mellitus, 13 had thyroid problems, 20 had hypercholesterolemia or a combination. A postoperative frozen shoulder was noted after arthroscopic stabilization $(n=1)$, arthroscopic release of frozen shoulder $(n=2)$, arthroscopic rotator cuff repair $(n=2)$, arthroscopic needling of calcifications $(n=3)$, and arthroscopic decompression $(n=2)$. Eleven patients had a frozen shoulder associated with calcific tendinitis; 4 had a partial rotator cuff tear, one had pulmonary disease, and two had cardiac disease. One patient had stiffness after a shoulder dislocation, and 13 patients developed stiffness after minor trauma (contusion, fall on the shoulder without fracture). Twenty-six patients were not previously treated for their frozen shoulder. Forty-four patients had undergone previous non-operative treatment consisting of infiltrations $(n=28)$, physiotherapy $(n=23)$, failed hydrodilatation $(n=1)$. Two patients presented with a persistent frozen shoulder after a failed arthroscopic release.

\section{Objective One: Temporal effects between hydrodilatation and objective indices of shoulder functionality and subjective outcomes of pain, mobility, kinesiophobia, depression, and anxiety}

The CMS shoulder increased significantly $(p<0.001)$ from 46.2 $(\mathrm{SD}=13.0)$ at $\mathrm{T} 1$ to $72.0(\mathrm{SD}=16.9)$ at $\mathrm{T} 3$, indicating an average improvement of 25.8 points $(95 \% \mathrm{CI}=21.8-29.8)$. Table 1 displays the changes in shoulder functionality indices at different time points. All mobility parameters show a significant $(p<0.001)$ improvement from T1 to T2 and T3. Pain and disability, as indicated by the SPADI, decreased significantly $(p<0.001)$ from $33.1 \quad(\mathrm{SD}=9.6)$ and $48.6(\mathrm{SD}=17.7)$ to $18.0(\mathrm{SD}=13.0)$ and $23.0(\mathrm{SD}=21.7)$, respectively (mean reduction pain $=15.9, \quad 95 \% \mathrm{CI}=12.4-17.8$, mean reduction disability $=25.6,95 \% \mathrm{CI}=21.4-29.9$ ). 
Table 1 Univariate changes in indices of shoulder functionality parameters at different time-points

\begin{tabular}{|c|c|c|c|c|c|c|c|c|}
\hline \multirow[t]{2}{*}{ Functional parameter } & \multicolumn{2}{|l|}{$T_{1 \text { (pre) }}$} & \multicolumn{2}{|c|}{$T_{2 \text { (post) }}$} & \multicolumn{2}{|c|}{$T_{3 \text { (3 months post) }}$} & \multirow[t]{2}{*}{$F^{a}$} & \multirow{2}{*}{$\begin{array}{l}\text { Significant } \\
\text { pairwise } \\
\text { comparisons }\end{array}$} \\
\hline & $M$ & $S D$ & $M$ & $S D$ & $M$ & $S D$ & & \\
\hline Active abduction & 94.8 & 26.8 & 114.2 & 35.2 & 150.1 & 35.7 & $61.6^{* * *}$ & $\mathrm{~T}_{1}<\mathrm{T}_{2}, \mathrm{~T}_{1}<\mathrm{T}_{3}, \mathrm{~T}_{2}<\mathrm{T}_{3}$ \\
\hline Active anteflexion & 112.6 & 19.8 & 128.4 & 27.6 & 158.0 & 23.8 & $83.2^{* * *}$ & $T_{1}<T_{2}, T_{1}<T_{3}, T_{2}<T_{3}$ \\
\hline Active external rotation & 30.5 & 14.0 & 47.2 & 13.7 & 51.9 & 17.4 & $60.1^{* * *}$ & $\mathrm{~T}_{1}<\mathrm{T}_{2}, \mathrm{~T}_{1}<\mathrm{T}_{3}, \mathrm{~T}_{2}<\mathrm{T}_{3}$ \\
\hline Active internal rotation & 16.0 & 3.0 & 14.1 & 4.7 & 9.3 & 6.0 & $47.7^{* * *}$ & $T_{1}>T_{2}, T_{1}>T_{3}, T_{2}>T_{3}$ \\
\hline Passive abduction & 81.3 & 25.3 & 96.7 & 33.1 & 99.1 & 23.0 & $18.7^{* * *}$ & $\mathrm{~T}_{1}<\mathrm{T}_{2}, \mathrm{~T}_{1}<\mathrm{T}_{3}$ \\
\hline Passive anteflexion & 103.3 & 22.2 & 118.0 & 27.0 & 121.8 & 26.1 & $20.2^{* * *}$ & $\mathrm{~T}_{1}<\mathrm{T}_{2}, \mathrm{~T}_{1}<\mathrm{T}_{3}$ \\
\hline Passive external rotation & 26.7 & 13.6 & 41.0 & 15.1 & 38.1 & 16.2 & $37.9^{* * *}$ & $\mathrm{~T}_{1}<\mathrm{T}_{2}, \mathrm{~T}_{1}<\mathrm{T}_{3}$ \\
\hline Passive internal rotation & 32.8 & 23.2 & 52.6 & 17.6 & 53.1 & 24.4 & $25.6^{* * *}$ & $\mathrm{~T}_{1}<\mathrm{T}_{2}, \mathrm{~T}_{1}<\mathrm{T}_{3}$ \\
\hline
\end{tabular}

Note: $T 1$ before HD, $T 2$ immediately after HD, $T 33$ months after HD, M Mean, SD Standard Deviation

${ }^{a} \mathrm{~F}$-test based on the independent pairwise comparisons among the estimated marginal means

*** $p<0.001$

Females reported a stronger decrease in pain (17.5 versus $10.8, p=0.016)$ and mobility scores (29.1 versus 19.0 , $p=0.023)$ on the SPADI than males. The VAS pain score decreased significantly $(p<0.001)$ from 5.3 (SD 2.4) at T1 to $2.4(\mathrm{SD}=2.8)$ at $\mathrm{T} 3$ (mean reduction $2.9,95 \% \mathrm{CI}=2.3-$ 3.5). The type of frozen shoulder did not influence these effects.

Patients with a longer duration of symptoms reported higher levels of pain and disability on the SPADI $(r=0.29-0.30$ range $)$ and VAS $(r=0.26)$ at T1 and less favorable change at T3 on the CMS and VAS. Depression (mean reduction $1.5,95 \% \mathrm{CI}=0.9-2.1$ ), and anxiety (mean reduction $1.1,95 \% \mathrm{CI}=0.5-1.7$ ) improved significantly $(p<0.001)$ between T1 and T3. Kinesiophobia improved significantly for females (mean reduction $3.0,95 \% \mathrm{CI}=2.0-4.1, p<0.001$ ), but not for males $(95 \% \mathrm{CI}=-1.7-3.1, p=0.568)$.

\section{Objective Two: To investigate the reciprocal temporal effects between objective and subjective outcomes of hydrodilatation and kinesiophobia, depression, and anxiety}

When considering reciprocal effects between the examined outcomes of hydrodilatation and respectively, kinesiophobia (Table 2), depression (Table 3), and anxiety (Table 4), psychological factors were more likely to predict outcomes of hydrodilatation than vice versa. Specifically, kinesiophobia, depression, and anxiety at T1 significantly predicted worse outcomes at T3 on the VAS and active abduction. Kinesiophobia and depression also predicted a lower CMS and active anteflexion score, whereas depression and anxiety were predictive of a higher residual disability index at $\mathrm{T} 3$.
Several psychological factors were also uniquely related to the outcomes of hydrodilatation. Kinesiophobia at $\mathrm{T} 1$ increased the probability of a less positive effect of hydrodilatation on subjective pain, assessed with the SPADI, and the shoulder functionality indices active external rotation, active internal rotation, and passive abduction. Depression also predicted worse passive anteflexion and internal rotation scores at T3. Conversely, none of the objective and subjective measures at $\mathrm{T} 1 \mathrm{sig}$ nificantly predicted depression at T3. Furthermore, of all the assessed prospective associations, only active abduction and active and passive internal rotation were significantly predictive of kinesiophobia and/or anxiety.

\section{Discussion}

This is the first prospective study to investigate the associations between kinesiophobia, depression, and anxiety and clinical outcomes of a validated treatment option in frozen shoulder patients. Our study seems to confirm the good short-term functional scores after hydrodilatation in patients with frozen shoulder. A fast improvement of the ROM is seen together with a decrease of pain levels. This is in concordance with a study by Yoon et al. [27]. In their series, hydrodilatation also yielded a rapid improvement of mobility and decreased pain after three months. However, after six months, no significant differences were noted between hydrodilatation and subacromial or intra-articular corticosteroid injection. The rapid treatment effect is the main reason why hydrodilatation is our preferred non-operative treatment option for frozen shoulder. Most frozen shoulder patients already suffer for a long time, and a direct improvement in pain and mobility is often a stimulus to continue physiotherapy to regain a normal ROM. Here, a longer duration of symptoms 
Table 2 The reciprocal effects between objective and subjective outcomes of hydrodilatation and kinesiophobia

\begin{tabular}{|c|c|c|c|}
\hline Predictor at $\mathrm{t} 1$ & $\beta$ & $95 \% \mathrm{BCl}$ & Outcome at $\mathrm{t} 3$ \\
\hline \multicolumn{4}{|c|}{ Objective and subjective outcomes at 3-month follow-up } \\
\hline CMS total & $0.37^{*}$ & $.08 ; 0.70$ & CMS Total \\
\hline Kinesiophobia & $-0.89^{*}$ & $-1.44 ;-0.34$ & \\
\hline SPADI_Pain & $0.62^{*}$ & $0.33 ; 0.91$ & SPADI_Pain \\
\hline Kinesiophobia & $0.58^{*}$ & $0.13 ; 1.01$ & \\
\hline SPADI_Disability & $0.66^{*}$ & $0.43 ; 0.90$ & SPADI_Disability \\
\hline Kinesiophobia & 0.59 & $-0.21 ; 1.33$ & \\
\hline VAS_Pain & $0.48^{*}$ & $0.25 ; 0.72$ & VAS_Pain \\
\hline Kinesiophobia & $0.10^{*}$ & $0.02 ; 0.17$ & \\
\hline Active abduction & 0.03 & $-0.21 ; 0.27$ & Active Abduction \\
\hline Kinesiophobia & $-2.30^{*}$ & $-3.52 ;-1.33$ & \\
\hline Active Anteflexion & 0.07 & $-0.21 ; 0.37$ & Active Anteflexion \\
\hline Kinesiophobia & $-1.28^{*}$ & $-2.04 ;-0.61$ & \\
\hline Active external rotation & $0.31^{*}$ & $0.01 ; 0.64$ & Active External Rotation \\
\hline Kinesiophobia & $-0.74^{*}$ & $-1.29 ;-0.27$ & \\
\hline Active internal rotation & 0.38 & $-0.02 ; 1.00$ & Active Internal Rotation \\
\hline Kinesiophobia & $0.39^{*}$ & $0.18 ; .0 .58$ & \\
\hline Passive abduction & -0.08 & $-0.31 ;-0.22$ & Passive Abduction \\
\hline Kinesiophobia & $-1.00^{*}$ & $-1.85 ;-0.09$ & \\
\hline Passive Anteflexion & 0.23 & $-0.15 ; 0.63$ & Passive Anteflexion \\
\hline Kinesiophobia & 0.3 & $-0.89 ; 1.61$ & \\
\hline $\begin{array}{l}\text { Passive external rota- } \\
\text { tion }\end{array}$ & 0.35 & $-0.02 ; 0.66$ & Passive External Rotation \\
\hline Kinesiophobia & -0.43 & $-0.92 ; 0.04$ & \\
\hline $\begin{array}{l}\text { Passive internal rota- } \\
\text { tion }\end{array}$ & $0.31^{*}$ & $0.01 ; 0.64$ & Passive Internal Rotation \\
\hline Kinesiophobia & -0.42 & $-1.04 ; 0.22$ & \\
\hline \multicolumn{4}{|c|}{ Psychological outcomes at 3-month follow-up } \\
\hline CMS Total & -0.01 & $-.11 ; .09$ & Kinesiophobia \\
\hline Kinesiophobia & $0.92^{*}$ & $0.73 ; 1.07$ & \\
\hline SPADI_Pain & 0.09 & $-0.05 ; 0.24$ & Kinesiophobia \\
\hline Kinesiophobia & $0.89^{*}$ & $0.67 ; 1.06$ & \\
\hline SPADI_Disability & 0.02 & $-0.05 ; 0.09$ & Kinesiophobia \\
\hline Kinesiophobia & $0.90^{*}$ & $0.70 ; 1.08$ & \\
\hline VAS_Pain & 0.20 & $-0.27 ; 0.66$ & Kinesiophobia \\
\hline Kinesiophobia & $0.90^{*}$ & $0.71 ; 1.07$ & \\
\hline Active Abduction & $0.06^{*}$ & $0.02 ; 0.10$ & Kinesiophobia \\
\hline Kinesiophobia & $0.98^{*}$ & $0.80 ; 1.15$ & \\
\hline Active Anteflexion & 0.03 & $-0.05 ; 0.10$ & Kinesiophobia \\
\hline Kinesiophobia & $0.95^{*}$ & $0.79 ; 1.10$ & \\
\hline $\begin{array}{l}\text { Active External Rota- } \\
\text { tion }\end{array}$ & 0.03 & $-0.04 ; 0.11$ & Kinesiophobia \\
\hline Kinesiophobia & $0.93^{*}$ & $0.75 ; 1.08$ & \\
\hline Active Internal Rotation & $-0.29^{*}$ & $-0.54 ;-0.04$ & Kinesiophobia \\
\hline Kinesiophobia & $0.95^{*}$ & $0.77 ; 1.12$ & \\
\hline Passive Abduction & 0.02 & $-0.04 ; 0.07$ & Kinesiophobia \\
\hline Kinesiophobia & $0.94^{*}$ & $0.76 ; 1.09$ & \\
\hline Passive Anteflexion & 0.02 & $-0.03 ; 0.07$ & Kinesiophobia \\
\hline Kinesiophobia & $0.93^{*}$ & $0.75 ; 1.09$ & \\
\hline
\end{tabular}

Table 2 (continued)

\begin{tabular}{llll}
\hline Predictor at t1 & $\boldsymbol{\beta}$ & $\mathbf{9 5 \%} \mathbf{B C l}$ & Outcome at t3 \\
\hline $\begin{array}{l}\text { Passive External Rota- } \\
\text { tion }\end{array}$ & 0.03 & $-0.05 ; 0.12$ & Kinesiophobia \\
Kinesiophobia & $0.92^{*}$ & $0.74 ; 1.09$ & \\
$\begin{array}{l}\text { Passive Internal Rota- } \\
\text { tion }\end{array}$ & 0.01 & $-0.04 ; 0.08$ & Kinesiophobia \\
Kinesiophobia & $0.93^{*}$ & $0.75 ; 1.07$ & \\
\hline
\end{tabular}

Note: Significance is based on $95 \%$ bias-corrected and accelerated bootstrap confidence intervals $(\mathrm{BCl})$. All regressions controlled for age, sex, and type of frozen shoulder (not shown in this table for ease of interpretation)

was associated with a lower functional result. This can be explained by the fact that patients with long-standing mobility impairment probably have a very thickened glenohumeral capsule that withstands hydrodilatation. In general, the good functional result after hydrodilatation also resulted in the better psychological well-being of frozen shoulder patients, with significantly lower levels of pain, anxiety, and depression. However, a longer duration of symptoms negatively influenced the psychological outcome with higher levels of kinesiophobia, more anxiety/ depression, and more pain/disability three months after the hydrodilatation.

The most important aim of this study was to investigate the reciprocal temporal effects between objective and subjective outcomes of hydrodilatation and kinesiophobia, depression, and anxiety. We hypothesized that hydrodilatation would lead to a decrease in subjective outcomes of pain and an increase in mobility, but such that higher levels of depression and/or anxiety would attenuate this improvement. This was especially true for kinesiophobia and depression. In addition, we anticipated that an improvement in objective and subjective clinical parameters would lead to less kinesiophobia, depression, and anxiety at a three-month follow-up assessment, but this was generally not confirmed. Koorevaar et al. also noted that psychological symptoms persisted in 56\% of patients after surgical treatment [17]. Similarly, they found that psychological disorders one year postoperatively were associated with a worse clinical outcome. Our results suggest that improvement in psychological factors may improve the outcomes of hydrodilation but did not found evidence for the reverse direction. The latter suggests that mental health improvement is likely driven by more factors than those measured in this study.

\section{Study limitations}

The current findings should be interpreted in the context of several limitations. First, we only evaluated the possible effect of psychological factors on the outcome of one type of treatment for frozen shoulder 
Table 3 The reciprocal effects between objective and subjective outcomes of hydrodilatation and depression

\begin{tabular}{|c|c|c|c|}
\hline Predictor at $\mathrm{t} 1$ & $\beta$ & $95 \% \mathrm{BCl}$ & Outcome at $\mathrm{t} 3$ \\
\hline \multicolumn{4}{|c|}{ Objective and subjective outcomes at 3-month follow-up } \\
\hline CMS total & $0.30^{*}$ & $0.01 ; 0.61$ & CMS Total \\
\hline Depression & $-1.74^{*}$ & $-3.16 ;-0.20$ & \\
\hline SPADI_Pain & $0.65^{*}$ & $0.41 ; 0.91$ & SPADI_Pain \\
\hline Depression & 0.67 & $-0.10 ; 1.51$ & \\
\hline SPADI_Disability & $0.63^{*}$ & $0.43 ; 0.84$ & SPADI_Disability \\
\hline Depression & $1.29^{*}$ & $0.09 ; 2.48$ & \\
\hline VAS_Pain & $0.48^{*}$ & 0.28 .0 .69 & VAS_Pain \\
\hline Depression & $0.18^{*}$ & $0.04 \cdot 0.32$ & \\
\hline Active abduction & 0.03 & -0.22 .0 .28 & Active Abduction \\
\hline Depression & $-2.95^{*}$ & $-5.26 .-0.81$ & \\
\hline Active Anteflexion & 0.09 & $-0.19 ; 0.40$ & Active Anteflexion \\
\hline Depression & $-1.55^{*}$ & $-3.37 ;-0.04$ & \\
\hline $\begin{array}{l}\text { Active external rota- } \\
\text { tion }\end{array}$ & 0.29 & $-0.02 ; 0.59$ & Active External Rotation \\
\hline Depression & -0.65 & $-1.78 ; 0.45$ & \\
\hline Active internal rotation & $0.49^{*}$ & $0.01 ; 1.08$ & Active Internal Rotation \\
\hline Depression & 0.37 & $-0.04 ; 0.72$ & \\
\hline Passive abduction & -0.13 & $-0.34 ; 0.16$ & Passive Abduction \\
\hline Depression & -2.05 & $-3.60 ; 0.14$ & \\
\hline Passive anteflexion & 0.10 & $-0.30 ; 0.49$ & Passive Anteflexion \\
\hline Depression & $-2.31^{*}$ & $-4.02 ;-0.63$ & \\
\hline $\begin{array}{l}\text { Passive external rota- } \\
\text { tion }\end{array}$ & 0.31 & $-0.05 ; 0.63$ & Passive External Rotation \\
\hline Depression & -0.51 & $-1.37 ; 0.55$ & \\
\hline $\begin{array}{l}\text { Passive internal rota- } \\
\text { tion }\end{array}$ & 0.30 & $-0.02 ; 0.640$ & Passive Internal Rotation \\
\hline Depression & $-1.35^{*}$ & $-2.44 ;-0.04$ & \\
\hline \multicolumn{4}{|c|}{ Psychological outcomes at 3-month follow-up } \\
\hline CMS Total & 0.00 & $-0.06 ; 0.05$ & Depression \\
\hline Depression & $0.72^{*}$ & $0.51 ; 0.88$ & \\
\hline SPADI_Pain & 0.03 & $-0.04 ; 0.10$ & Depression \\
\hline Depression & $0.70^{*}$ & $0.49 ; 0.84$ & \\
\hline SPADI_Disability & 0.01 & -0.03 .0 .05 & Depression \\
\hline Depression & $0.71^{*}$ & 0.49 .0 .86 & \\
\hline VAS_Pain & -0.02 & -0.25 .0 .23 & Depression \\
\hline Depression & $0.73^{*}$ & 0.52 .0 .86 & \\
\hline Active abduction & 0.00 & $-0.02 ; 0.03$ & Depression \\
\hline Depression & $0.73^{*}$ & $0.52 ; 0.86$ & \\
\hline Active anteflexion & 0.02 & $-0.01 ; 0.05$ & Depression \\
\hline Depression & $0.75^{*}$ & $0.53 ; 0.88$ & \\
\hline $\begin{array}{l}\text { Active external rota- } \\
\text { tion }\end{array}$ & -0.01 & $-0.05 ; 0.04$ & Depression \\
\hline Depression & $0.72^{*}$ & $0.52 ; 0.86$ & \\
\hline Active internal rotation & -0.20 & $-0.42 ; 0.01$ & Depression \\
\hline Depression & $0.74^{*}$ & $0.54 ; 0.87$ & \\
\hline Passive abduction & -0.01 & $-0.03 ; 0.00$ & Depression \\
\hline Depression & $0.70^{*}$ & $0.48 ; 0.84$ & \\
\hline Passive anteflexion & 0.00 & $-0.02 ; 0.02$ & Depression \\
\hline Depression & $0.73^{*}$ & $0.50 ; 0.86$ & \\
\hline
\end{tabular}

Table 3 (continued)

\begin{tabular}{|c|c|c|c|}
\hline Predictor at $\mathrm{t} 1$ & $\beta$ & $95 \% \mathrm{BCl}$ & Outcome at $\mathrm{t} 3$ \\
\hline $\begin{array}{l}\text { Passive external rota- } \\
\text { tion }\end{array}$ & 0.03 & $-0.02 ; 0.09$ & Depression \\
\hline Depression & $0.76^{*}$ & $0.55 ; 0.09$ & \\
\hline $\begin{array}{l}\text { Passive internal rota- } \\
\text { tion }\end{array}$ & -0.01 & $-0.03 ; 0.02$ & Depression \\
\hline Depression & $0.72^{*}$ & $0.52 ; 0.86$ & \\
\hline
\end{tabular}

Note: Significance is based on $95 \%$ bias-corrected and accelerated bootstrap confidence intervals $(\mathrm{BCl})$. All regressions controlled for age, sex, and type of frozen shoulder (not shown in this table for ease of interpretation)

and did not consider prior treatments. Since this is a referral hospital, most frozen shoulder patients have already run through a physiotherapy and/or injections program, so the beneficial effect of the hydrodilatation might also be partially attributed to the previous therapy. However, this effect is probably minimal, as patients would otherwise not have sought further treatment. Further, the fact that the patients did not have the same physiotherapist to perform the prescribed rehabilitation at home might have created a bias. However, it was not practically possible to provide supervised physiotherapy with the same physiotherapist in one center in our clinical setting. Second, as we did not have a control group, findings regarding treatment outcomes of hydrodilatation should be interpreted tentatively. Relatedly, we used convenience sampling of patients who presented to our Orthopaedic Upper Limb Clinic with a frozen shoulder between September 2014 and January 2018 while the sample size was not predetermined based on apriori power analyses. Hence, future research is needed to evaluate the generalizability and replicability of the present findings. Third, although it is a clinical reality that the group frozen shoulders are heterogeneous, this might be a confounding factor regarding in our analyses of treatment outcomes and its relationship with psychological parameters. Furthermore, it should be acknowledged that the sample size in the present study was too low to conduct any meaningful subgroup analyses of lagged effects between patients with primary and secondary frozen shoulder and those with and without a prior treatment history. This represents an important direction for future research. Fourth, the follow-up time after hydrodilatation was only three months. Consequently, we cannot comment on the long-term effects of this treatment. However, Fareed et al. reported sustainable effects up to ten years after hydrodilatation [14]. Similarly, Nicholson et al. observed low repeat intervention rates after hydrodilatation at long-term follow-up [18]. Fifth, some patients had a duration of symptoms of less than 
Table 4 The reciprocal effects between objective and subjective outcomes of hydrodilatation and anxiety

\begin{tabular}{|c|c|c|c|}
\hline Predictor at $\mathrm{t} 1$ & $\beta$ & $95 \% \mathrm{BCl}$ & Outcome at $\mathrm{t} 3$ \\
\hline \multicolumn{4}{|c|}{ Objective and subjective outcomes at 3-month follow-up } \\
\hline CMS total & $0.44^{*}$ & $0.12 ; 0.77$ & CMS Total \\
\hline Anxiety & -1.11 & $-2.35 ; 0.23$ & \\
\hline SPADI_Pain & $0.72^{*}$ & $0.50 ; 0.98$ & SPADI_Pain \\
\hline Anxiety & 0.57 & $-0.34 ; 1.40$ & \\
\hline SPADI_Disability & $0.72^{*}$ & $0.53 ; 0.90$ & SPADI_Disability \\
\hline Anxiety & $1.27^{*}$ & $0.03 ; 2.31$ & \\
\hline VAS_Pain & $0.54^{*}$ & $0.35 ; 0.75$ & VAS_Pain \\
\hline Anxiety & $0.14^{*}$ & $0.01 ; 0.28$ & \\
\hline Active abduction & 0.07 & $-0.19 ; 0.33$ & Active Abduction \\
\hline Anxiety & $-3.41^{*}$ & $-5.58 ;-1.43$ & \\
\hline Active anteflexion & 0.14 & $-0.15 ; 0.45$ & Active Anteflexion \\
\hline Anxiety & -1.29 & $-2.77 ; 0.06$ & \\
\hline $\begin{array}{l}\text { Active external rota- } \\
\text { tion }\end{array}$ & 0.31 & $-0.00 ; 0.62$ & Active External Rotation \\
\hline Anxiety & -0.35 & $-1.66 ; 1.11$ & \\
\hline Active internal rotation & $0.51^{*}$ & $0.04 ; 1.14$ & Active Internal Rotation \\
\hline Anxiety & 0.24 & $-0.18 ; 0.60$ & \\
\hline Passive abduction & -0.13 & $-0.36 ; 0.18$ & Passive Abduction \\
\hline Anxiety & -2.22 & $-4.15 ; 0.39$ & \\
\hline Passive anteflexion & 0.16 & $-0.23 ; 0.56$ & Passive Anteflexion \\
\hline Anxiety & -1.77 & $3.57 ; 0.14$ & \\
\hline $\begin{array}{l}\text { Passive external rota- } \\
\text { tion }\end{array}$ & 0.34 & $-0.04 ; 0.67$ & Passive External Rotation \\
\hline Anxiety & -0.46 & $-1.52 ; 0.73$ & \\
\hline $\begin{array}{l}\text { Passive internal rota- } \\
\text { tion }\end{array}$ & 0.30 & -0.02 .0 .63 & Passive Internal Rotation \\
\hline Anxiety & -0.63 & $-1.94 \cdot 0.76$ & \\
\hline \multicolumn{4}{|c|}{ Psychological outcomes at 3-month follow-up } \\
\hline CMS total & -0.02 & $-0.07 ; 0.04$ & Anxiety \\
\hline Anxiety & $0.77^{*}$ & $0.59 ; 0.93$ & \\
\hline SPADI_Pain & 0.03 & $-0.03 ; 0.10$ & Anxiety \\
\hline Anxiety & $0.77^{*}$ & $0.60 ; 0.93$ & \\
\hline SPADI_Disability & 0.02 & $-0.01 ; 0.05$ & Anxiety \\
\hline Anxiety & $0.77^{*}$ & $0.59 ; 0.93$ & \\
\hline VAS_Pain & 0.09 & $-0.16 ; 0.036$ & Anxiety \\
\hline Anxiety & $0.78^{*}$ & $0.60 ; 0.94$ & \\
\hline Active abduction & 0.00 & $-0.03 ; 0.02$ & Anxiety \\
\hline Anxiety & $0.78^{*}$ & $0.60 ; 0.93$ & \\
\hline Active anteflexion & -0.01 & $-0.04 ; 0.02$ & Anxiety \\
\hline Anxiety & $0.77^{*}$ & $0.59 ; 0.94$ & \\
\hline $\begin{array}{l}\text { Active external rota- } \\
\text { tion }\end{array}$ & 0.02 & $-0.02 ; 0.07$ & Anxiety \\
\hline Anxiety & $0.79^{*}$ & $0.60 * 0.96$ & \\
\hline Active internal rotation & -0.13 & $-0.34 ; 0.07$ & Anxiety \\
\hline Anxiety & $0.79^{*}$ & $0.61 ; 0.96$ & \\
\hline Passive abduction & -0.01 & $-0.03 ; 0.01$ & Anxiety \\
\hline Anxiety & $0.76^{*}$ & $0.56 ; 0.94$ & \\
\hline Passive anteflexion & -0.02 & $-0.04 ; 0.01$ & Anxiety \\
\hline Anxiety & $0.76^{*}$ & $0.56 ; 0.93$ & \\
\hline
\end{tabular}

Table 4 (continued)

\begin{tabular}{llll}
\hline Predictor at t1 & $\boldsymbol{\beta}$ & $\mathbf{9 5 \%} \mathbf{~ B C l}$ & Outcome at t3 \\
\hline $\begin{array}{l}\text { Passive external rota- } \\
\text { tion }\end{array}$ & 0.03 & $-0.02 ; 0.09$ & Anxiety \\
$\begin{array}{l}\text { Anxiety } \\
\text { Passive internal rota- }\end{array}$ & $0.04^{*}$ & 0.01 .0 .07 & Anxiety \\
tion & & & \\
Anxiety & $0.82^{*}$ & 0.64 .0 .99 &
\end{tabular}

Note: Significance is based on $95 \%$ bias-corrected and accelerated bootstrap confidence intervals $(\mathrm{BCl})$. All regressions controlled for age, sex, and type of frozen shoulder (not shown in this table for ease of interpretation

six months. These would be classified in the frozen shoulder's inflammatory stage, whereas those with a longer duration of symptoms would be in the freezing or frozen phase. One could argue that a hydrodilatation in the early inflammatory phase would be too painful for the patients. However, in our experience, the presence of a local anesthetic and corticosteroids in the hydrodilatation cocktail provides enough pain relief in these patients. Finally, we used self-reported scores to evaluate the psychological well-being of our patients. Social desirability bias can be an issue when patients want to picture themselves in a socially more acceptable manner.

\section{Conclusion}

We observed a significant improvement in functionality, pain, and disability following hydrodilatation and found that kinesiophobia, depression, and anxiety predict the treatment outcome of hydrodilatation on frozen shoulder symptomatology. Awaiting future research on this timely topic, the present finding suggests that knowledge of frozen shoulder patients' psychological well-being might help guide the most suitable treatment strategy.

\section{Acknowledgements \\ Not applicable.}

\section{Authors' contributions}

PD, FV, WD and LC initiated and planned the study. PD, WD supervised the study. PD, FV, IDC, OC collected the data. IDC, OC, DT, GK, LC analyzed the data. PD, LC, GK wrote the manuscript, FV and WD added to the manuscript. The author(s) read and approved the fnal manuscript.

\section{Funding}

No funding was obtained for this study.

\section{Availability of data and materials}

The datasets generated and analyzed during the current study are available from the authors on reasonable request.

\section{Declarations}

Ethics approval and consent to participate

All participants provided written informed consent before inclusion in the study. This study was approved by the Full Local Research and Ethical Committee of the University Hospital of Leuven (B322201421602; S56800). 


\section{Consent for publication}

Informed consent to use data and diagnostic images was obtained.

\section{Competing interests}

The authors declare that they have no confict of interest.

\section{Conflict of interest}

None declared.

\section{Author details}

1 Orthopedics, University Hospitals Leuven, Herestraat 49, B-3000 Leuven, Belgium. ${ }^{2}$ Department of Development and Regeneration, KU Leuven, Leuven, Belgium. ${ }^{3}$ Institute for Orthopaedic Research and Training, Leuven, Belgium. ${ }^{4}$ Musculoskeletal Research Unit, Department of Rehabilitation Sciences, Faculty of Kinesiology and Rehabilitation Sciences, KU Leuven, Leuven, Belgium. ${ }^{5}$ Faculty of Psychology and Educational Sciences, KU Leuven, Leuven, Belgium. ${ }^{6}$ Faculty of Medicine and Health Sciences, University Antwerp, Antwerp, Belgium. ${ }^{7}$ Department of Neurosciences, Center for Contextual Psychiatry, KU Leuven, Leuven, Belgium.

Received: 3 June 2021 Accepted: 19 August 2021

Published online: 30 September 2021

\section{References}

1. Abrassart S, Kolo F, Piotton S, Chih-Hao Chiu J, Stirling P, Hoffmeyer P, Lädermann A (2020) 'Frozen shoulder' is ill-defined. How can it be described better? EFORT Open Rev. 5(5):273-279. https://doi.org/10 1302/2058-5241.5.190032

2. Andren L, Lundberg BJ (1965) Treatment of rigid shoulders by joint distension during arthrography. Acta Orthop Scand 36:45-53

3. Bjelland I, Dehl AA, Haug TT, Neckelmann D (2002) The validity of the hospital anxiety and depression scale. An updated literature review. J Psychosom Res 52(2):69-77. https://doi.org/10.1016/S0022-3999(01)00296-3

4. Buchbinder R, Green S (2004) Effect of arthrographic shoulder joint distension with saline and corticosteroid for adhesive capsulitis. Br I Sports Me 38(4):384-385. https://doi.org/10.1136/bjsm.2004.013532

5. Cho CH, Seo HJ, Bae KC, Lee KJ, Hwang I, Warner JJ (2013) The impact of depression and anxiety on self-assessed pain, disability, and quality of life in patients scheduled for rotator cuff repair. J Shoulder Elbow Surg 22(9):1160-1166. https://doi.org/10.1016/j.jse.2013.02.006

6. Cho CH, Song KS, Hwang I, Warner JJ (2015) Does rotator cuff repair improve psychologic status and quality of life in patients with rotator cuff tear? Clin Orthop Relat Res 473(11):3494-3500. https://doi.org/10.1007/ s11999-015-4258-1

7. Constant CR, Gerber C, Emery RJ, Sojbjerg JO, Gohlke F, Boileau P (2008) A review of the constant score: modifications and guidelines for its use. J Shoulder Elbow Surg 17(2):355-361. https://doi.org/10.1016/j.jse.2007.06. 022

8. Crichlow RJ, Andres PL, Morrison SM, Haley SM, Vrahas MS (2006) Depression in orthopaedic trauma patients. Prevalence and severity. J Bone Joint Surg Am 88(9):1927-33. https://doi.org/10.2106/JBJS.D.02604

9. De Das S, Vranceanu AM, Ring DC (2013) Contribution of kinesophobia and catastrophic thinking to upper-extremity-specific disability. J Bone Joint Surg Am 95(1):76-81. https://doi.org/10.2106/JBJS.L.00064

10. Debeer P, Franssens F, Roosen I. Dankaerts W. Claes L (2014) Frozen shoulder and the Big Five personality traits. J Shoulder Elbow Surg 23(2):221-226. https://doi.org/10.1016/j.jse.2013.07.049

11. Dekker AP, Salar O, Karuppiah SV, Bayley E, Kurian J (2016) Anxiety and depression predict poor outcomes in arthroscopic subacromial decompression. J Shoulder Elbow Surg 25(6):873-880. https://doi.org/10.1016/j. jse.2016.01.031

12. Ding H, Tang Y, Xue Y, Yang Z, Li Z, He D, Zhao Y, Zong Y (2014) A report on the prevalence of depression and anxiety in patients with frozen shoulder and their relations to disease status. Psychol Health Med 19(6):730-737. https://doi.org/10.1080/13548506.2013.873814

13. Ebrahimzadeh MH, Moradi A, Bidgoli HF, Zarei B (2019) The relationship between depression or anxiety symptoms and objective and subjective symptoms of patients with frozen shoulder. Int J Prev Med 10:38. https:// doi.org/10.4103/ijpvm.JJPVM_212_17

14. Fareed DO, Gallivan WR Jr (1989) Office management of frozen shoulder syndrome. Treatment with hydraulic distension under local anesthesia. Clin Orthop Relat Res 242:177-183

15. Gallacher S, Beazley JC, Evans J, Anaspure R, Silver D, Redfern A, Thomas W, Kitson J, Smith C (2018) A randomized controlled trial of arthroscopic capsular release versus hydrodilatation in the treatment of primary frozen shoulder. J Shoulder Elbow Surg 27(8):1401-1406. https://doi.org/10. 1016/j.jse.2018.04.002

16. Koorevaar RC, van 't TerluinRiet BE, Madden K, Bulstra SK (2016) Validation of the four-dimensional symptom questionnaire (4DSQ) and prevalence of psychological symptoms in orthopedic shoulder patients. J Orthop Res 34(4):683-691. https://doi.org/10.1002/jor.23051

17. Koorevaar RC, van't Riet E, Gerritsen MJ, Madden K, Bulstra SK (2016) The influence of preoperative and postoperative psychological symptoms on clinical outcome after shoulder surgery: A Prospective Longitudinal Cohort Study. PLoS ONE 11(11):e0166555. https://doi.org/10.1371/journ al.pone.0166555

18. Nicholson JA, Slader B, Martindale A, Mckie S, Robinson CM (2020) Distension arthrogram in the treatment of adhesive capsulitis has a low rate of repeat intervention. Bone Joint J. 102-B(5):606-610. https://doi.org/10. 1302/0301-620X.102B5.BJJ-2020-0082

19. Thorpe AM, O'Sullivan PB, Mitchell T, Hurworth M, Spencer J, Booth G, Goebel S, Khoo P, Tay A, Smith A (2018) Are psychologic factors associated with shoulder scores after rotator cuff surgery? Clin Orthop Relat Res 476(10):2062-2073. https://doi.org/10.1097/CORR.00000000000000389

20. Tveitå EK, Tariq R, Sesseng S, Juel NG, Bautz-Holter E (2008) Hydrodilatation, corticosteroids and adhesive capsulitis: a randomized controlled trial. BMC Musculoskelet Disord 19(9):53. https://doi.org/10.1186/ 1471-2474-9-53

21. Watson L, Bialocerkowski A, Dalziel R, Balster S, Burke F, Finch C (2007) Hydrodilatation (distension arthrography): a long-term clinical outcome series. Br J Sports Med 41(3):167-173. https://doi.org/10.1136/bjsm.2006. 028431

22. Weekes DG, Campbell RE, Shi WJ, Giunta N, Freedman KB, Pepe MD, Tucker BS, Tjoumakaris FP (2019) Prevalence of clinical depression among patients after shoulder stabilization: a prospective study. J Bone Joint Surg Am 101(18):1628-1635. https://doi.org/10.2106/JBJS.18.01460

23. Williams JW Jr, Holleman DR Jr, Simel DL (1995) Measuring shoulder function with the shoulder pain and disability index. J Rheumatol 22(4):727-732

24. Woby SR, Roach NK, Urmston M, Watson PJ (2005) Psychometric properties of the TSK-11: a shortened version of the Tampa Scale for Kinesiophobia. Pain 117(1-2):137-144. https://doi.org/10.1016/j.pain.2005.05.029

25. Wolfensberger A, Vuistiner P, Konzelmann M, Plomb-Holmes C, Léger B, Luthi F (2016) Clinician and patient-reported outcomes are associated with psychological factors in patients with chronic shoulder pain. Clin Orthop Relat Res 474(9):2030-2039. https://doi.org/10.1007/ s11999-016-4894-0

26. Wong CK, Levine WN, Deo K, Kesting RS, Mercer EA, Schram GA, Strang BL (2017) Natural history of frozen shoulder: fact or fiction? A systematic review. Physiotherapy 103(1):40-47. https://doi.org/10.1016/j.physio. 2016.05.009

27. Yoon JP, Chung SW, Kim JE, Kim HS, Lee HJ, Jeong WJ, Oh KS, Lee DO, Seo A, Kim Y (2016) Intra-articular injection, subacromial injection, and hydrodilatation for primary frozen shoulder: a randomized clinical trial. J Shoulder Elbow Surg 25(3):376-383. https://doi.org/10.1016/j.jse.2015.11. 009

28. Zuckerman JD, Rokito A (2011) Frozen shoulder: a consensus definition. J Shoulder Elbow Surg 20:322-325. https://doi.org/10.1016/j.jse.2010.07. 008

\section{Publisher's Note}

Springer Nature remains neutral with regard to jurisdictional claims in published maps and institutional affiliations. 